\title{
A literature review on community-acquired methicillin-resistant Staphylococcus aureus in the United States: Clinical information for primary care nurse practitioners
}

\author{
Barbara E. Barnes, RN, MS, CNE (Graduate Student, Family Nurse Practitioner Program) ${ }^{1}$ \\ \& Deborah A. Sampson, PhD, FNP-BC (Assistant Professor) ${ }^{2}$ \\ 1 Rackham School of Nursing, University of Michigan, Harrietta, Michigan \\ 2 The University of Michigan School of Nursing, Ann Arbor, Michigan
}

\author{
Keywords \\ Community-associated methicillin-resistant \\ Staphylococcus aureus; MRSA; primary care \\ nurse practitioner; infectious disease; infection \\ prevention and control; colonization.

\section{Correspondence} \\ Barbara E. Barnes, RN, MS, CNE, Rackham \\ School of Nursing, University of Michigan, 2901 \\ S. 9 1/2 Road, Harrietta, MI 49638. \\ Tel: 231-876-3603; \\ E-mail: barbara.barnes@baker.edu \\ Received: June 2009; \\ accepted: October 2009
}

doi: 10.1111/j.1745-7599.2010.00571.x

\begin{abstract}
Purpose: To analyze the state of the science of community-associated methicillin-resistant Staphylococcus aureus (CA-MRSA) in the United States to support the integration of current knowledge for primary care nurse practitioners' (PCNP) practice.

Data sources: Published research limited to U.S. studies in MEDLINE, CINAHL, and Cochrane Review from 1950 to the week of September 4, 2008. Investigations were identified through electronic search engines and databases. Manual searches were done of hard copy references in journal articles. Citations and reference lists for English language research studies of CA-MRSA in the United States were reviewed to identify additional research that fit evaluation criteria for this analysis.

Conclusions: Until the late 1990s, healthcare-associated MRSA (HA-MRSA) was the predominant cause of serious infections. Recently, CA-MRSA has caused infections in previously healthy nonhospitalized people. Major demographic and epidemiological differences exist between the two types of resistant bacteria; the emergence of CA-MRSA suggests new implications for primary care.

Implications for practice: PCNPs will undoubtedly treat MRSA infections and need a comprehensive understanding of the pathogenicity, diagnosis, and management of CA-MRSA to ensure expedient and appropriate treatment. This will help to prevent invasive disease as a result of improperly treated infections.
\end{abstract}

Fleming's discovery of penicillin in 1929 heralded a new method for treatment of Staphylococcus aureus (SA) infections, the most common cause of postsurgical and soft tissue infections in the United States. Although penicillin was effective, it was expensive to produce and was not widely used until the 1940s when available mass production methods of penicillin lowered the cost, allowing the drug to be used to treat both civilians and wounded soldiers during World War II.

However, by the 1950s resistance to the treatment emerged as a result of plasmid-mediated penicillinase production by some strains of SA. In response to the penicillin resistance, methicillin was introduced for SA treatment in 1959. However, within a year, methicillinresistant SA (MRSA) developed in the United Kingdom (Halem, Trent, Green, \& Kerdel, 2006; Jevons, 1961). By the 1970s, healthcare-associated methicillin-resistant SA (HA-MRSA), formerly known as hospital acquired MRSA, was endemic in many U.S. hospitals and extended care facility (ECF) residents, primarily affecting the elderly and the chronically ill (Centers for Disease Control and Prevention [CDC], 2006a).

It soon appeared that methicillin resistance was not limited to healthcare facilities and geriatric populations. In 1981 in Detroit, Michigan, MRSA was identified in community-dwelling intravenous drug users (IVDUs; 
CDC, 1981). Healthcare providers became more concerned when community-associated methicillin-resistant SA (CA-MRSA) infections caused the deaths of four children in the United States in 1999 (CDC, 1999). The public became acutely aware of the organism when USA Today reported an MRSA infection outbreak among the St. Louis Rams (Milhoces, 2005). Since then, media reports have increased public awareness of CA-MRSA. In addition, community-associated strains of MRSA bacteria are now the cause of many serious healthcare-associated infections (Gonzalez et al., 2006).

Although not fully understood, the resistance of SA and Staphylococcus epidermis (SE) to antibiotics may be attributed to the increasing use of antibiotics. This antibiotic use, coupled with the fact that beta-lactam antibiotics are excreted by sweat, can stimulate the staphylococci bacteria normally on the skin to develop beta-lactam resistance (Holby, Pers, Johansen, and the Copenhagen study group of Antibiotics in Sweat, 2000). Such constantly evolving knowledge about CA-MRSA presents a challenge to advanced practice nurses (APN) who provide inpatient and outpatient care. Obtaining the most current knowledge about the prevention of CA-MRSA disease transmission is a vital step toward reducing suffering, minimizing healthcare costs, and avoiding loss in productivity.

Although much has been published about the treatment and management of HA-MRSA, a comprehensive overview of the state of the science of CA-MRSA and the implications for patient care by primary care nurse practitioners (PCNPs) has received less attention. Therefore, this article describes CA-MRSA pathophysiology, treatment, and management in the United States and implications for PCNPs and MRSA treatment.

\section{Epidemiology}

Detailed information on the studies of incidence and prevalence of MRSA is included in Table S1. Studies have focused on incidence and prevalence of CA- and HAMRSA in various locations across the United States. The following section is a summary of the studies reviewed.

\section{SA and MRSA colonization}

Two major population-based studies conducted in the United States on the National Health and Nutrition Examination Survey (NHANES) data from 2001 to 2002 determined SA and MRSA colonization prevalence rates. Both authors (Graham, Lin, \& Larson, 2006; Kuehnert et al., 2006) published independently analyzed results in 2006 with similar conclusions: in 2001-2002 just over $30 \%$ of the U.S. noninstitutionalized population was colonized with SA, while less than $1 \%$ were colonized with
MRSA. However, since 2002, incidence and prevalence of both HA-MRSA and CA-MRSA have increased dramatically (Bartels, Boye, Larsen, Skove, \& Westh, 2007; Stevenson, Searle, Stoddard, \& Samore, 2005; Vandenesch et al., 2003).

\section{MRSA and CA-MRSA in health care}

In the United States, 94,360 invasive MRSA infections occurred in 2005, causing 18,650 deaths. Of the 94,360 infections, $75.2 \%$ were bacteremias, $26.6 \%$ of these bacteremias were hospital onset, while $7 \%$ specifically represented CA-MRSA invasive disease (Klevens et al., 2007). The incidence of MRSA infections in healthcare settings is as high as 40\% (Kiran et al., 2006). The 1992-2002 National Nosocomial Infection Surveillance (NNIS) reported that MRSA accounted for more than $53 \%$ of all hospital SA isolates (NNIS, 2002).

\section{HA-MRSA infection and colonization}

A national point-prevalence study conducted within U.S. healthcare facilities during October and November 2006 found that 46 out of every 1000 hospitalized patients were either colonized or infected with MRSA, a rate eight to 11 times greater than previously estimated (CDC, 2007a). Theoretically, HA-MRSA spreads into the community when hospitalized patients colonized with HAMRSA are discharged (Salgado, Farr, \& Calfee, 2003). Therefore, HA-MRSA is increasing both in healthcare settings and in the community.

\section{CA-MRSA infection in health care}

CA-MRSA is epidemic in many regions of the United States (Purcell \& Fergie, 2005). The incidence of CAMRSA reported in both inpatient and outpatient settings vary. For example, in a population-based surveillance, Baltimore CA-MRSA disease incidence was 18/100,000, while CA-MRSA isolate incidence in Atlanta was 24.7/100,000 (Fridkin et al., 2005). In Chicago, CAMRSA hospital infection incidence increased over a 5 year period from 24/100,000 to 164.2/100,000 (Hota et al., 2007). Approximately $60 \%$ of all U.S. emergency department SA skin and soft tissue infections (SSTIs) are caused by MRSA (Moran et al., 2006); however, primary care settings, especially pediatric settings, are also experiencing increases in MRSA skin infections (Hersh et al., 2009; Hinckley \& Allen, 2008). Because CA-MRSA is identified in healthcare facilities, experts predict that this trend could eventually lead to increased severity of CAMRSA infections among hospitalized patients (D'Agata, Webb, Horn, Moellering, \& Ruan, 2009). 


\section{CA-MRSA colonization among outpatients and in the community}

The prevalence of CA-MRSA varies. An outpatient colonization prevalence study found that $12.3 \%$ of all SA isolates were MRSA (Jernigan, Pullen, Partin, \& Jarvis, 2003). A more recent outpatient infection prevalence study compared community-associated methicillinsensitive SA (CA-MSSA) and CA-MRSA infections in four hospital outpatient settings (William Beaumont, MI; Henry Ford, MI; Pittsburg Veterans Administration Medical Center, PA; and Rush University Medical Center, IL) and found the overall prevalence of MRSA to be $26.7 \%$ of all SA infections (Davis et al., 2007). A population-based CA-MRSA prevalence study conducted among the urban poor identified a $2.8 \%$ CA-MRSA colonization prevalence (Charlebois et al., 2002).

\section{Population risk factors}

CA-MRSA has been described in people who are often at risk of other infections because of living situations, economic and/or health disparities, or life style. For example, military personnel (Ellis, Hospenthal, Dooley, Paula, \& Clinton, 2004), prisoners (CDC, 2003), the homeless, the urban poor, and residents of public housing (Charlebois et al., 2002), men who have sex with men (MSM) (Iyer $\&$ Jones, 2004; Lee et al., 2005), and IVDUs are considered to be among such high-risk groups. Transmission may also occur in athletic settings or in daycare through the sharing of personal items, such as toys, towels, and razors (Cohen, 2005), or living in close quarters such as in military settings or prison (Ellis et al., 2004; CDC, 2003).

It is likely that CA-MRSA transmission is related to skin-to-skin contact, lifestyle-such as IVDU or methamphetamine use (Cohen et al., 2007; Miller et al., 2005)and poor hygiene (Calfee et al., 2003; Dinusha, Auld, \& Mermel, 2004). Higher incidences have also been described in African Americans (Fridkin et al., 2005; Ochoa, Mohr, Wanger, Murphy, \& Heresi, 2005), Native Americans (Cookson, 2000; Groom et al., 2001; Ofner-Agostini, Simore, Bryce, McGeer, \& Paton, 2006), and children (Herold et al., 2007), particularly children who attend daycare (Dinusha et al., 2004; Fergie \& Purcell, 2001; Lee et al., 2004). However, it is unclear whether it is the physical settings or independent risk factors of individuals or specific populations that are the causes for higher incidence.

\section{Antibiotic resistance and microbial genetics}

Because of their genotypic differences, HA-MRSA and CA-MRSA do not manifest the same clinical virulence patterns or antibiotic resistance. The differences are caused by genetic factors that affect patient illness, antibiotic resistance, and treatment.

All SA bacteria have a mobile genetic element known as Staphylococcal cassette chromosome (SCCmec). A subset of a larger SCCmec gene, the $m e c A$ gene and its variation determines the antibiotic differences between HAMRSA and CA-MRSA bacteria. Although both possess $m e c A$ genes, there are differences in the genetic sequence that create variances in the bacteria's resistance levels (Donnio, Prendy, Lerestif, Avril, \& Lafforgue, 2004). Consequently, mecA gene determination is one method by which CA-MRSA is differentiated from HA-MRSA (Bell, 2008).

Further, beta-lactam resistance occurs as a result of the SA mecA gene production of the penicillin binding peptide (PBP2a), which decreases bacterial affinity to beta-lactams (Donnio et al., 2004). Therefore, each organism will require different treatment. For example, HA-MRSA is only sensitive to certain antibiotics and should be treated with vancomycin, linozelid, and daptomycin (Loffler \& MacDougall, 2007). On the other hand, CA-MRSA exhibits more susceptibility to additional classes of antibiotics such as tetracycline (doxycline), trimethoprim-sulfamethoxazole (TMX/SMP), gentamycin, and clindamycin (Loffler \& MacDougall, 2007) as a result of the type of SCC $\operatorname{mec} A$ gene found in CA-MRSA.

CA-MRSA antibiotic resistance is increasing. Emergence of resistance to clindamycin during treatment for CA-MRSA (inducible resistance) is described in several published reports (Hulten et al., 2006; MartinezAguilar et al., 2004). However, certain types of CA-MRSA infections are less resistant and therefore easier to treat. For example, pediatric CA-MRSA isolates were significantly less resistant than were adult isolates to clindamycin, ciprofloxin, gentamycin, and tetracycline (David et al., 2006). Adult CA-MRSA infections should rarely be treated with these antibiotics, and providers should carefully monitor MRSA antibiotic susceptibility patterns for pediatric and adult patients within the community.

The CA-MRSA SCC mec gene complex differs from the HA-MRSA mec gene complex in yet another way, the presence or absence of toxin genes (Naimi et al., 2003). Nearly all strains of SA secrete substances that convert host tissues into the nutrients needed for bacterial growth. However, some strains produce additional substances, known as toxins, that are responsible for serious clinical manifestations such as necrotizing disease and aggressive tissue destruction.

Toxin genes are present in CA-MRSA worldwide (Wannet et al., 2004). These genes are considered 
key virulence determinants factors in CA-MRSA disease (Gonzolez et al., 2005; Wang et al., 2007). CA-MRSA is characterized by a toxin, known as Panton-Valentine leukocidin (PVL), which causes leukocyte destruction, tissue necrosis, and complicated, virulent infections such as necrotizing myositis, faciitis empyema, septic emboli, and pneumonia (Boubaker et al., 2008; Gonzalez et al., 2005; Miller et al., 2005). Treatment for CA-MRSA pneumonia is different from community-onset pneumonia as a result of other organisms because it is necrotizing, producing hemoptysis, and lung cavitation and must be treated with a toxin-suppressing antibiotic, such as clindamycin (Hidron, Low, Honig, \& Blumberg, 2009). The presence of toxin genes causes CA-MRSA infections to be more aggressive and invasive in healthier patients as compared with patients affected by HA-MRSA.

In addition, toxin genes have been found worldwide in both CA-MSSA and CA-MRSA infections (Vandenesch et al., 2003). One strain of CA-MRSA is nearly identical to a form of SA that caused a pandemic in 1950s (Robinson et al., 2005); therefore, CA-MRSA may not be a new strain but may represent reemergence of older strains of SA. Contrary to popular belief, microbiologically, CA-MRSA bacterium is more like CA-MSSA than like HA-MRSA (Sattler, Mason, \& Kaplan, 2002).

Both CA-MSSA and CA-MRSA infections exhibit very similar clinical symptoms such as abscesses, cellulitis, furuncles, and both types of community-associated SA are more invasive and virulent than HA-MRSA infections (Miller et al., 2007), causing serious disease in healthier, younger age groups (Robinson et al., 2005). HA-MRSA does not present as necrotizing disease but rather manifests instead as chronic wounds, decubitus ulcers, pneumonia, urinary tract infections, and bacteremia (BoyleVavra \& Daum, 2007; Boyle-Vers, Ereshefsy, Wang, \& Daum, 2005; Buescher, 2005; Zaoutis et al., 2006).

Finally, the smaller CA-MRSA mec gene is more mobile and probably more transmissible between host bacteria. This characteristic may enhance the spread of the organism between individuals because the smaller CA-MRSA SCCmecA gene allows mobile genetic elements (DNA) within CA-MRSA to move quickly and easily between other SA chromosomes (Carleton, Diep, Charlebois, Sensabaugh, \& Perdreau-Remington, 2004). Although CA-MRSA may be easier to treat, CA-MRSA is also more easily spread than is HA-MRSA.

\section{Patient care aspects \\ Infection}

CA-MRSA most often manifests as SSTIs. Like MSSA SSTIs, CA-MRSA frequently occurs as abscess(es) (Pur- cell $\&$ Fergie, 2005), furuncles, and carbuncles (Fridkin et al., 2005; Micek, Dunne, \& Kollef, 2005; Moran, Amii, Abrahamian, \& Talan, 2005). These can occur at single or multiple sites and are accompanied by signs and symptoms of infection such as pain, fever, and malaise. In addition, patients may present with other CA-MRSA draining manifestations, such as persistent acute otitis media with or without ottorhea. In these cases, culturing of drainage before initiating treatment is imperative. The appearance of the infection provides few clues about the infecting organism.

\section{Diagnosing and treating CA-MRSA infection}

Limited information exists on specific treatment of CAMRSA infections, as opposed to other soft tissue infections. Instead, many experts encourage treating all SSTI in the same way until cultures can identify the infecting organism. For example, regardless of the suspected organism, some experts suggest that biopsy and culture of the advancing edge of induration or cellulitis should be performed for organism identification (IDPH, 2008; Winland-Brown, Porter, \& Leik, 2007) or a needle aspiration for fluid culture should be considered (CDC, 2006b). It is important to understand that the national recommendations help to guide practice.

In its publication, Guidelines for SSTIs, The Infectious Diseases Society of America (IDSA) recommends incision and drainage (IED) of purulence and application of heat as the most effective treatment of abscesses regardless of the infecting organism (Stevens et al., 2005). Culturing the drainage before initiating treatment is imperative to verify the pathogen in any infection (Al-Shawwa $\delta$ Wegner, 2005; Bell, 2008; CDC, 2006b). Antibiotic management of CA-MRSA is different from infections caused by HA-MRSA; therefore, it is important to differentiate the organism through culture and susceptibility confirmation to determine whether CA-MRSA is susceptible to less costly antimicrobials and leave more expensive antibiotics (linazelid, vancomycin, or daptomycin) as last resorts (Loffler \& MacDougall, 2007).

Empiric treatment of CA-MRSA is recommended while waiting for confirmation through culture, regardless of where the patient presents for treatment. As a result of increased awareness, many outpatient settings are beginning to practice current recommendations. Although considerable variations exist in the treatment patterns of MRSA (Conly et al., 2003), recent primary care recommendations emphasize IED and culturing drainage as a standard of practice in outpatient clinics, emergency departments, and primary care offices (Hersh et al., 2009; Moran et al., 2006). Incision and drainage of abscesses that are less than $5 \mathrm{~cm}$ can resolve the infection without 
Table 1 Treatment of CA-MRSA

\begin{tabular}{|c|c|c|}
\hline Immunocompetent afebrile with abscesses & Immunocompetent febrile* with abscesses & $\begin{array}{l}\text { Immunocompromised** and/or bacteremia, } \\
\text { endocarditis, septic shock, or } \\
\text { osteomyolitis, may require hospitalization }\end{array}$ \\
\hline I\&D to verify pathogen & I\&D to verify pathogen & Infectious disease consultation \\
\hline Hot packs & Hot packs & Treat with: IV vancomycin*** 1000 mg every \\
\hline In lesion(s) >5 cm treat with: & In lesion(s) > $5 \mathrm{~cm}$ treat with: & $12 \mathrm{~h}$ OR daptomycin 6 mg/kg IV every $24 \mathrm{~h}$. \\
\hline $\begin{array}{l}\text { Two* trimethoprim/sulfamethoxazole } \\
\text { (TMP/SMX) double strength (DS) twice daily OR } \\
\text { doxycycline or minocycline } 100 \mathrm{mg} \times 10-14 \\
\text { days }\end{array}$ & $\begin{array}{l}\text { Two* TMPISMX DS twice daily } \times 10-14 \text { days } \\
\text { with or without rifampin } 300 \text { mg twice daily or } \\
600 \mathrm{mg} \text { once daily OR linozolid } 600 \mathrm{mg} \text { orally or } \\
\text { intravenously (IV) twice daily or one dose of } \\
\text { dalbavancin } 1000 \mathrm{mg} \mathrm{IV}\end{array}$ & \\
\hline
\end{tabular}

*Febrile-acute onset of temperature $>101.3^{\circ} \mathrm{F}\left(38.5^{\circ} \mathrm{C}\right)$, associated with signs and symptoms of bacterial infection (Porter, Jones, Winland-Brown, 2007) *Treatment failures have been reported when using one TMPISMX DS bid (Iyer \& Jones, 2004; Cenizal et al., 2007).

**Some types of immunocompromised patients are cancer patients undergoing chemotherapy, patients on chronic steroid use, transplant patients, HIV-positive patients, splenectomy patients, and diabetic patients. Although many of these types of patients will respond to I\&D alone or with oral CA-MRSA specific antibiotics, it may be necessary for inpatient treatment.

*** The IDSA guidelines for (2005) suggest dosing vancomycin at $30 \mathrm{mg} / \mathrm{kg}$ in two divided doses or daptomycin $4 \mathrm{mg} / \mathrm{kg}$ every $24 \mathrm{~h}$ for adults (Stevens et al., 2005). It is imperative to monitor peak and trough levels and creatinine clearance levels in patients undergoing vancomycin therapy.

antibiotics, including those caused by CA-MRSA (Daum, 2007; Rejendran et al., 2007), or when an antibiotic, such as a beta-lactam, is used empirically (Dooley, Barnes, Hepburn, \& Baum, 2006). Therefore, I\&D rather than antibiotic use, is the first line of treatment for localized uncomplicated CA-MRSA skin infections (Miller et al., 2007). Other treatment after incision includes the use of hot packs on the infection site as well as patient education about proper skin hygiene (Stevens et al., 2005).

Uncomplicated CA-MRSA SSTI infections are easily managed (Zafar et al., 2007). As already mentioned, these sites respond well to I\&D. Still severe morbidity or mortality can occur if the infection is not appropriately treated in a timely manner (Marcinak \& Frank, 2003; Micek et al., 2005; Rihn et al., 2005). Unlike local SSTI, invasive CA-MRSA infections can be difficult to eradicate and may result in significant mortality (Kiran et al., 2006; Klevens et al., 2007). Consequently, serious CAMRSA infections should be referred to an infectious disease expert for management; they will likely need treatment with intravenous vancomycin (Dooley et al., 2006). Although the actual number of invasive CA-MRSA infections within healthcare settings is low, approximately $13.7 \%$ (Klevens et al., 2007), invasive CA-MRSA infections in the healthcare settings are on the rise (Gonzalez et al., 2006; Maree, Daum, Boyle-Vavra, Matayoshi, \& Miller, 2007).

\section{Antibiotic management}

Current recommendations from the CDC (2007b) and The Sanford Guide to Antimicrobial Therapy 2008, 38th edition
(Gilbert, Moellering, Eliopoulos, \& Sande, 2008) for outpatient treatment of CA-MRSA include a step management approach depending on the seriousness of the infection, patient symptoms, and the underlying condition of the patient. The CDC recommendations for the treatment of CA-MRSA are guidelines often used by practitioners. However, The Sanford Guide to Antimicrobial Therapy, which incorporates both national standards and rapidly emerging resistance patterns, is updated and released annually and thus, may provide more current treatment guidelines. The 2008 recommendations from The Sanford Guide to Antimicrobial Therapy 2008, 38th edition for treatment of CA-MRSA include the following (see Table 1 for more detail):

- Outpatient treatment for immunocompetent, afebrile patients with abscesses includes application of hot packs and in abscesses greater than $5 \mathrm{~cm}$, antibiotic treatment with two oral TMP/SMX double strength (DS) twice daily or doxycycline or minocycline $100 \mathrm{mg}$ twice daily for 10-14 days (Gilbert et al., 2008).

- Outpatient treatment for CA-MRSA abscesses, immunocompetent, febrile patients would include hot packs as well as two oral TMP/SMX DS twice daily for 10-14 days with or without rifampin $300 \mathrm{mg}$ twice daily or $600 \mathrm{mg}$ once daily or linozolid 600 mg orally or intravenously (IV) twice daily or one dose of dalbavancin 1000 mg IV (Gilbert et al., 2008).

- Any patients more serious than this (e.g., patients who are immunocompromised, or have 
bacteremia, endocarditis, septic shock, or osteomyolitis) may require hospitalization, infectious disease consultation, and IV vancomycin $1000 \mathrm{mg}$ every $12 \mathrm{~h}$ if no impairment in renal function or daptomycin $6 \mathrm{mg} / \mathrm{kg}$ IV (Gilbert et al., 2008; Rybak et al., 2009).

Patients allergic to sulfonamides should be treated with doxycycline or minocycline with rifampin (Gilbert et al., 2008). Finally, because of the potential for inducible resistance when used as monotherapy, rifampin should never be used alone to treat MRSA (Bubacz, 2007; CDC, 2006b).

\section{Colonization and decolonization}

While high levels of microbes are present in active infection, colonization indicates that microbes are present but in low levels that do not produce illness. HA-MRSA and CA-MRSA colonization can be detected most frequently in nasal passages (Kenner et al., 2003; Kuehnert et al., 2006), axilla, groin, perineum, and rectum (Eveillard, Lassence, Barnaud, Ricard, \& Joly-Guillou, 2006).

Even though colonization does not represent infection or active disease, colonization with CA-MRSA in healthy individuals can later predispose these individuals to CA-MRSA infections (Datta \& Huang, 2008; Zaoutis et al., 2006). Further, transmission of CA-MRSA to others and environmental contamination can occur in both the infected and colonized patient. The use of antibiotics and antimicrobial cleansing agents to eradicate CA-MRSA from an individual and/or environment, also known as decolonization, has limited efficacy because many individuals may recolonize in less than a year (Simor et al., 2007). Efficient decolonization can be difficult and expensive to implement; therefore, it may be impractical as a control strategy.

\section{Control of transmission}

The CDC guidelines (2006) for infection prevention and control of CA-MRSA are primarily applicable to healthcare settings. Although there are contact precaution recommendations for prevention of transmission of CAMRSA within the community that emphasize hand hygiene, wound coverage, and environmental cleaning (CDC, 2008), contact isolation recommendations for the prevention of MRSA transmission by restricting patients from public encounters within community settings do not exist.

Research on other methods of control and detection has just begun. Therefore, until further research delineates specific guidelines, transmission management of
CA-MRSA in the primary care setting should include basic hygiene measures; hand washing, containment of drainage, proper disposal of contaminated dressings, and good personal hygiene. Because the risks and benefits of potential transmission in community settings have yet to be fully evaluated, patients should be instructed on how to limit contact with others (family, co-workers, and the public) if the wound drainage cannot be contained.

PCNPs should conduct a risk assessment on the patients affected by CA-MRSA. Other sources of potential MRSA reservoir should also be identified such as athletic facilities or day care centers. Although there are no published studies on MRSA carriage in pets, there is anecdotal evidence that pets harbored MRSA in recurrent human cases (Duijkeren et al., 2004; Kim \& Del Rossa, 2008; Manian, 2003; Weese et al., 2006). Most of these cases resolved when the animal was identified as the MRSA carrier and properly treated by a veterinarian.

Although PCNPs will play a role in educating the patient and family on proper cleansing of the environment, there is little research about CA-MRSA to support approaches to personal hygiene and environmental disinfection. Therefore, if a patient or family member has recurrent episodes of CA-MRSA infections or colonization, a referral should be made to an infectious disease specialist (Calfee et al., 2003; Zafar et al., 2007).

\section{Conclusions}

Since the discovery of penicillin, antibiotics have saved lives and reduced suffering. However, bacterial adaptation against antibiotic efficacy has raised new patient treatment problems. This review demostrates that there are considerable variations in antibiotic treatment recommendations for CA-MRSA among experts. As bacterial resistance to common antibiotics continues to evolve, PCNPs need to stay informed about the most current recommendations for identification and management of multidrug-resistant organism infections. Moreover, patients with any SSTI should be treated conservatively with I\&D of abcesses, warm soaks to the infected area, and proper wound care regardless of the causative organism. Such treatment usually resolves infection without increasing antibiotic use.

The incidence and prevalence of CA-MRSA in the United States is increasing and disease severity varies from simple, uncomplicated SSTIs to invasive, necrotizing infections. CA-MRSA causes serious disease in healthier and younger populations than those currently considered at risk for HA-MRSA. These trends stimulate ongoing media attention; the public has more questions and concerns than ever about antibiotic-resistant bacteria. Because CAMRSA infections exhibit symptoms that are similar to 
other types of SA infections, it is impossible to make the distinction between causative organisms without a culture and sensitivity. However, empiric treatment in primary care and outpatient settings may be started while awaiting results of the culture.

PCNPs will be called upon to treat MRSA infections and will need a comprehensive understanding of the differences and similarities in pathogenicity, diagnosis, and management of HA-MRSA and CA-MRSA. An additional purpose of this article was to compare and contrast HAMRSA and CA-MRSA treatment and management.

Research on primary care of patients affected by CAMRSA in the United States is limited; trends in such research findings and the resulting practice recommendations from that research will guide primary care practice. The PCNP is in an important position to address the care of patients affected by CA-MRSA and should be knowledgeable about the best research-based methods and expert recommendations. This knowledge can promote best practices in treatment and community education while helping to reduce transmission of CA-MRSA among individuals. However, continued research on CAMRSA is needed to increase knowledge of the organism, improve primary care treatment and management of patients affected by the organism while reducing suffering, containing healthcare costs, and preventing losses in productivity.

\section{Acknowledgments}

A special acknowledgement to N. Joel Ehrenkrenz, MD, for his valuable input into the history of MRSA and to my supportive director, Bonnie Schreiber, RN, BSN, and helpful colleagues at Munson Medical Center, Traverse City, Michigan.

\section{References}

Al-Shawwa, B., \& Wegner, D. (2005). Trimethoprim-sulfamethoxazole plus topical antibiotics as therapy for acute otitis media with otorrhea caused by community-acquired methicillin-resistant Staphylococcus aureus in children. Archives of Otolaryngology-Head $\theta$ Neck Surgery, 131(9), 782-784.

Bartels, M., Boye, K., Larsen, A., Skov, R., \& Westh, H. (2007). Rapid increase of genetically diverse meticillin-resistant Staphylococcus aureus, Copenhagen, Denmark. Emerging Infectious Diseases, 13(10), 1533-1540.

Bell, E. (2008). Infectious Disease News. Antibiotic choices for CA-MRSA infections. Retrieved November 24, 2008, from http://www.infectiousdiseasenews.com/200703/pharmconsult.asp

Boubaker, K., Diebold, P., Blanc, D., Vandenesch, F., Praz, G., \& Dupuis, G. (2008). Panton-valentine leukocidin and staphylococcal skin infections in schoolchildren. Emerging Infectious Diseases, 10(1), 121-124. Retrieved March 15, 2009, from www.cdc.gov/eid

Boyle-Vavra S., \& Daum R. S. (2007). Community-acquired methicillin-resistant Staphylococcus aureus: The role of panton-valentine leukocidin. Laboratory Investigation, 87(1), 3-9.

Boyle-Vers, S., Ereshefsky, B., Wang, C., \& Daum, R. (2005). Successful multiresistant community-associated methicillin-resistant Staphylococcus aureus linage from Taipei, Taiwan, that carries either the novel staphylococcal chromosome cassette mec (SCCmec) type Vt or Sccmec type IV. Journal of Clinical Microbiology, 43(9), 4719-4730.

Bubacz, M. (2007). Community-acquired methicillin-resistant Staphylococcus aureus: An ever-emerging epidemic. AAOHN Journal, 55(5), 193-194.

Buescher, E. (2005). Community-acquired methicillin-resistant Staphylococcus aureus in pediatrics. Clinical Infectious Diseases, 46(5), 5344-5349.

Calfee, D., Durbin, L., Germanson, T., Toney, D., Smith, E., \& Farr, B. (2003). Spread of methicillin-resistant Staphylococcus aureus (MRSA) among household contacts of individuals with nosocomially acquired MRSA. Infection Control and Hospital Epidemiology, 24(6), 422-426.

Carleton, H., Diep, B., Charlebois, E., Sensabaugh, G., \& Perdreau-Remington, F. (2004). Community-adapted methicillin-resistant Staphylococcus aureus (MRSA): Population dynamics of an expanding community reservoir of MRSA. Journal of Infectious Diseases, 190, 1730-1736.

Cenizal, M., Skiest, D., Luber, S., Bedimo, R., Davis, P., Fox, P., et al. (2007). Prospective randomized trial of empiric therapy with trimethoprim-sulfamethoxazole of doxycycline for outpatient skin and soft tissue infections in an area of high prevalence of methicillin-resistant Staphylococcus aureus. Antimicrobial Agents and Chemotherapy, 51(7), 2628-2630.

Centers for Disease Control and Prevention (CDC). (1981). Community-acquired methicillin-resistant Staphylococcus aureus infections-Michigan. MMWR weekly, Epidemiologic Notes and Reports, 30(16), 185-187.

Centers for Disease Control and Prevention. (1999). Four pediatric deaths from community-acquired methicillin-resistant Staphylococcus aureus-Minnesota and North Dakota, 1997-1999. Morbidity and Mortality Weekly Report, 48(32), 707-710.

Centers for Disease Control and Prevention. (2003). Methicillin-resistant Staphylococcus aureus in correctional facilities-Georgia, California, and Texas, 2001-2003. Department of Health and Human Services. MMWR weekly Report, 52(41), 992-996.

Centers for Disease Control and Prevention. (2006a). Management of multi-resistant organisms in the healthcare settings, 2006. Centers for Disease Control and Prevention. Department of Health and Human Services. Retrieved January 24, 2008, from http://www.cdc.gov/ncidod/dhqp/pdf/ ar/mdroGuideline2006.pdf

Centers for Disease Control and Prevention. (2006b). Strategies for clinical management of MRSA in the community: Summary of an experts' meeting convened by the Centers for Disease Control and Prevention. Centers for Disease Control and Prevention. Department of Health and Human Services. Retrieved January 24, 2008, from http://www.cdc.gov/ncidod/dhqp/pdf/ar/ CAMRSA_ExpMtgStrategies.pdf

Centers for Disease Control and Prevention. (2007a). National Prevalence Study of methicillin-resistant Staphylococcus aureus. Department of Health and Human Services. Retrieved July 14, 2008, from http://www.cdc.gov

Centers for Disease Control and Prevention. (2007b). Outpatient management of skin and soft tissue infections in the era of community-associated MRSA. Retrieved July 21, 2009, from http://www.cdc.gov/ncidod/dhqp/pdf/ ar/mrsaPosters/Flowchart_pstr.pdf

Centers for Disease Control and Prevention. (2008). Environmental managemen of staph and MRSA. Department of Health and Human Services. Retrieved January 09, 2009 from http://www.cdc.gov/ncidod/dhqp/ar_ mrsa_Enviro_Manage.html\#5

Charlebois, E., Bangsber, D., Moss, N., Moore, M., Chambers, H., \& Perdreau-Remington, F. (2002). Population-based community prevalence of methicillin-resistant Staphylococcus aureus in the urban poor of San Francisco. Clinical Infectious Diseases, 34, 425-432.

Cohen, P. (2005). Cutaneous community-acquired methicillin-resistant Staphylococcus aureus infection in participants of athletic activities. Southern Medical Association, 98(6), 596-602.

Cohen, A., Shuler, C., McAllister, Fosheim, G., Brown, M., Abercrombie, D., et al. (2007). Methamphetamine use and methicillin-resistant 
Staphylococcus aureus. Emerging Infectious Diseases, 13(11). Retrieved October 30, 2007, from http://www.cdc.gov/EID/content/13/11/ 1753.htm

Conly, J., Stiver, H., Weiss, K., Becker, D., Rosner, A., \& Miller, E. (2003). A retrospective analysis of practice patterns in the treatment of methicillin-resistant Staphylococcus aureus skin and soft tissue infections at three Canadian tertiary care centres. Canadian Journal of Infectious Diseases, 14(6), 315-320.

Cookson, B. (2000). Methicillin-resistant Staphylococcus aureus in the community: New battlefronts or are the battles lost? Infection Control $\theta$ Hospital Epidemiology, 21(6), 398-403.

D’Agata, E., Webb, G., Horn, M., Moellering, R., \& Ruan, S. (2009). Modeling the invasion of community-acquired methicillin-resistant Staphylococcus aureas into hospitals. Clinical Infection Diseases, 48(30), 274-284.

Datta, R., \& Huang, S. (2008). Risk of infection and death due to methicillin-resistant Staphylococcus aureus in long-term carriers. Clinical Infectious Diseases, 47, 176-181.

Daum, R. (2007). Skin and soft tissue infections caused by methicillin-resistant Staphylococcus aureus. Journal of the American Medical Association, 35(4), 380-390.

David, M., Crawford, S., Boyle-Vavra, S., Hostetler, M., Kim, D., \& Daum, R. (2006). Contrasting pediatric and adult methicillin-resistant Staphylococcus aureus isolates. Emerging Infectious Diseases, 12(4), 631-637.

Davis, S., Perri, M., Donabedian, S., Manierski, C., Singh, A., Vager, D., et al. (2007). Epidemiology and outcomes of community-acquired methicillin-resistant Staphylococcus aureus Infection. Journal of Clinical Microbiology, 45(6), 1705-1711.

Dinusha, D., Auld, D., \& Mermel, L. (2004). Community-acquired methicillin-resistant Staphylococcus aureus in southern New England children. Pediatrics, 113(4), 347-352.

Donnio, P., Preney, L., Gautiere-Lerestif, A., Avril, L., \& Lafforgue, N. (2004). Changes in staphylococcal cassette chromosome type and antibiotic resistance profile in methicillin-resistant Staphylococcus aureus isolates from a French hospital over an 11 year period. Journal of Antimicrobial Chemotherapy, 53, 808-813.

Dooley, D., Barnes, E., Hepburn, J., \& Baum, S. (2006). Outcomes of community-acquired, methicillin-resistant Staphylococcus aureus, soft tissue infections treated with antibiotics other than vancomycin. Military Medicine, 171, 504-507.

Duijkeren, E., Wolhagen, M., Box, A., Heck, M., Wim, J., Wannet, J., et al. (2004). Human-to-dog transmission of methicillin-resistant Staphylococcus aureus. Emerging Infectious Diseases, 10(12), 2235-2237.

Ellis, M., Hospenthal, D., Dooley, D., Paula, J., \& Clinton, K. (2004). Natural history of community-acquired methicillin-resistant Staphylococcus aureus colonization and infection in soldiers. Clinical Infectious Diseases, 39(7), 971-979.

Eveillard, M., Lassence, A., Barnaud, G., Ricard, J., \& Joly-Guillou, M. (2006) Evaluation of a strategy of screening multiple anatomical sites for methicillin-resistant Staphylococcus aureus at admission to a teaching hospital. Infection Control and Hospital Epidemiology, 27(2), 181-184.

Fergie, J., \& Purcell, K. (2001). Community-acquired methicilllin-resistant Staphylococcus aureus infections in south Texas children. Pediatric Infectious Disease Journal, 20(9), 860-863.

Fridkin, S., Hageman, J., Morrison, M., Sanza, L., Como-Sabetti, K., Jernigan, J., et al. (2005). Methicillin-resistant Staphylococcus aureus in three communities. New England Journal of Medicine, 352(14), $1436-1444$.

Gilbert, D., Moellering, R., Eliopoulos, G., Sande, M., \& Chambers, H. (2008). The Sanford guide to antimicrobial therapy 2008 (38th ed.). Portland: Oregon Health Services University.

Gonzalez, B., Hulten, K., Dishop, M. Lamberth, l., Hammerman, W., Mason, E., et al. (2005). Pulmonary manifestations in children with invasive community-acquired Staphylococcus aureus infection. Clinical Infectious Disease, 41, 583-590.

Gonzalez, B., Ruedia, A., Shelburne, S., Musher, D., Hamill, R., \& Hulten, K. (2006). Community-associated strains of methicilllin-resistant
Staphylococcus aureus as the cause of healthcare-associated infection. Infection Control and Hospital Epidemiology, 27(10), 1051-1056.

Graham, P., Lin, S., \& Larson, E. (2006). A U.S. population-based survey of Staphylococcus aureus colonization. Annals of Internal Medicine, 144, 318-325.

Groom, A., Wolsey, D., Naimi, T., Smith, K., Johnson, S., Boxrud, D., et al. (2001). Community-acquired methicillin-resistant Staphylococcus aureus in a rural American Indian community. Journal of the American Medical Association, 286(10), 1201-1207.

Halem, M., Trent, J., Green, J., \& Kerdel, F. (2006). Community-acquired methicillin resistant Staphylococcus aureus skin infection. Seminars in Cutaneous Medicine and Surgery, 25(2), 68-71.

Herold, B., Immergluck, L., Maranan, M., Lauderdale, K., Gaskin, R., Boyle-Vavra, S., et al. (2007). Community-acquired methicillin-resistant Staphylococcus aureus in children with no identified predisposing risk. Journal of the American Medical Association, 279(8), 593-598.

Hersh, L., Cabana, M., Gonzales, R., Shenkin, B., \& Cho, C. (2009). Pediatricians' perspectives on the impact of MRSA in primary care: A qualitative study. BMC Pediatrics 9(27). Retrieved July 21, 2009, from http://www.pubmedcentral.nih.gov/picrender.fcgi?artid=26715098 blobtype $=$ pdf

Hidron, A., Low, C., Honig, E., \& Blumberg, H. (2009). Emergence of community-acquired methicillin-resistant Staphylococcus aureus strain USA300 as a cause of necrotizing community onset pneumonia. Lancet Infectious Diseases, 9, 384-392.

Hinckley, J., \& Allen, P. (2008). Community-associated MRSA in the pediatric primary care setting. Pediatric Nursing. Retrieved July 21, 2009, from http://findarticles.com/p/articles/mi_m0FSZ/is_1_34/ai_n24923916/?tag= content;coll

Holby, N., Pers, C., Johansen, H., \& the Copenhagen study group of Antibiotics in Sweat. (2000). Excretion of B-lactam antibiotics in sweat-a neglected mechanism for development of antibiotic resistance? Antimicrobial Agents and Chemotherapy, 44(10), 2855-2857.

Hota, B., Ellenbogen, C., Hayden, M., Aroutcheva, A., Rice, T., \& Weinstein, R. (2007). Community-acquired methicillin-resistant Staphylococcus aureus skin and soft tissue infections at a public hospital. Arch Intern Med, 167, 1026-1033.

Hulten, K., Kaplan, S., Gonzalez, B., Hammerman, W. Lamberth, L., Versalovic, J., et al. (2006). Three-year surveillance of community onset health care-associated Staphylococcus aureus infections in children. Pediatric Infectious Disease Journal, 25(4), 39-353.

Illinois Department of Public Health (IDPH). (2008). Methicillin-resistant Staphylococcus aureus in Illinois: Guidelines for the primary care provider. Infectious Disease in Illinois. Retrieved January 9, 2009, from http://www.idph.state.il.us/health/infect/MRSA_Provider.htm

Iyer, S., \& Jones, D. (2004). Community-acquired methicillin-resistant Staphylococcus aureus skin infection: A retrospective analysis of clinical presentation and treatment of a local outbreak. Journal of the American Academy of Dermatology, 50(6), 854-858.

Jernigan, J., Pullen, A., Partin, C., \& Jarvis, W. (2003). Prevalence of and risk factors for colonization with methicillin-resistant Staphylococcus aureus in an outpatient clinic population. Infection Control and Hospital Epidemiology, $24(6), 445-450$.

Jevons, M. (1961). Celbenin resistant staphylococci. British Medical Journal, 1, 124-127.

Kenner, J., O'Conner, T., Piantanida, N., Fishbain, J., Eberly, B., Viscount, H., et al. (2003). Rates of carriage of methicillin-resistant and methicillin-susceptible Staphylococcus aureus in an outpatient population. Infection Control and Hospital Epidemiology, 24(6), 439-444.

Kim, G, \& Del Rosso, J. (2008). Community-acquired methicillin-resistant Staphylococcus aureus (CA-MRSA) Infections: Evaluation and management strategies. Skin and Aging. Retrieved January 10, 2008, from http://www.skinandaging.com/content/community-acquiredmethicillinresistant staphylococcus-aureus-ca-mrsainfections-evaluation

Kiran, R. V., McCampbell, B., Angeles, A., Montilla, R., Medina, C., Richard, D., et al. (2006). Increased prevalence of community-acquired 
methicillin-resistant Staphylococcus aureus in hand infections at an urban medical center. Plastic and Reconstructive Surgery, 118(1), 161-167.

Klevens, R., Morrison, M., Nadle, J., Petit, S., Gershman, K., Ray, S., et al. (2007). Invasive methicillin-resistant Staphylococcus aureus infections in the United States. Journal of the American Medical Association, 298(15), 1763-1771.

Kuehnert, M., Kruszon-Moran, D., Hill, H., McQuillan, G., McAllister, S., Fosheim, G., et al. (2006). Prevalence of Staphylococcus aureus nasal colonization in the United States, 2001-2002. Journal of Infectious Diseases, 193, 171-179.

Lee, M., Rios, A., Aten, M., Mejias, A., Cavuoti, D., Mccracken, Jr., G., et al. (2004). Community-acquired, methicillin-resistant and methicllin-susceptible Staphylococcus aureus musculoskeletal infections in children. Pediatric Infectious Disease Journal, 25(8), 701-706.

Lee, N., Taylor, M., Bancroft, E., Ruane, P., Morgan, M., McCoy, L., et al. (2005). Risk factors for community associated methicillin-resistant Staphylococcus aureus skin infections among HIV-positive men who have sex with men. Clinical Infectious Diseases, 40, 1529-1534.

Loffler, C., \& MacDougall, C. (2007). Update on prevalence and treatment of methicillin-resistant Staphylococcus aureus infections. Expert Review of Anti-infective Therapy, 5(6), 961-981.

Manian, F. (2003). Asymptomatic nasal carriage of mupirocin-resistant, methicillin-resistant staphylococcus aureus (MRSA) in a pet dog associated with MRSA infection in household contacts. Clinical Infectious Diseases, 36(2), E26-E28.

Marcinak, J., \& Frank, A. (2003) Treatment of community-acquired methicillin-resistant Staphylococcus aureus in children. Current Opinion in infectious Diseases, 16(3), 265-270.

Maree, C., Daum, R., Boyle-Vavra, S., Matayoshi, K., \& Miller, L. (2007). Community-associated methicillin-resistant Staphylococcus aureus isolates causing healthcare-associated infections. Emerging Infectious Diseases, 13(2), 236-242. Retrieved June 1, 2008, from www.cdc.gov/eid

Martinez-Aguilar, G., Avalos-Mishaan, A., Hulten, K., Hammerman, W., Mason, Jr., E., \& Kaplan, S. (2004). Clindamycin treatment of invasive infections cause by community-acquired methicillin resistant and methicillin-susceptible Staphylococcus aureus in children. Pediatric Infectious Disease Journal, 22(7), 593-598.

Micek, S., Dunne, M., \& Kollef, M. (2005). Pleuropulmonary complications of panton-valentine leukocidin-positive community-acquired methicillin-resistant Staphylococcus aureus: Importance of treatment with antimicrobials inhibiting exotoxin production. Chest, 128(4), $2732-2738$.

Milhoces, G. (2005). Teams keep eye on turf abrasions, staph infections. USA Today. Super Bowl XL. Retrieved October 10, 2008, from http://www.usatoday.com/sports/football/super/2005-02-03-staph_x.htm

Miller, L., Perdreau-Remington, F., Rieg, G., Mehdi, S., Perlroth, J., Bayer, A., et al. (2005). Necrotizing fasciitis caused by community-associated methicillin-resistant Staphylococcus aureus in Los Angeles. New England Journal of Medicine, 352 (14), 1445-1447.

Miller, L., Quan, C., Shay, A., Mostafaie, K., Bhardwa, K., Tan, N., et al. (2007). A prospective investigation of outcomes after hospital discharge for endemic, community acquired methicillin-resistant and -susceptible Staphylococcus aureus skin infection. Clinical Infectious Diseases, 44(15), 971-979.

Moran, G., Amii, R., Abrahamian, F., \& Talan, D. (2005). Methicillin-resistant Staphylococcus aureus in community acquired skin infections. Emerging Infectious Diseases, 11(6), 928-930.

Moran, G., Krishnadasan, A., Gorwitz, R., Fosheim, G., McDougal, L., Carey, R., et al. (2006). Methicillin-resistant S. aureus infections among patients in the emergency department. New England Journal of Medicine, 355, 664-674.

Naimi, T., LeDell, K., Como-Sabeti, K., Borchards, S., Boxrud, D., Etienne, J., et al. (2003). Comparison of community- and health care-associated methicillin resistant Staphylococcus aureus infection. Journal of the American Medical Association, 290(22), 2976-2984.

National Nosocomial Infections Surveillance. (2002). System report, data summary from January 1992-June 2002, issued August 2002. American Journal of Infection Control, 30, 458-475.

Ochoa, T., Mohr, J., Wanger, A., Murphy, J., \& Heresi, G. (2005). Community-associated methicillin-resistant Staphylococcus aureus in pediatric patients. Emerging Infectious Diseases, 11 (6), 966-968.

Ofner-Agostini, M., Simore, A., Bryce, E., McGeer, A., \& Paton, S. (2006). Methicillin-resistant Staphylococcus aureus in Canadian aboriginal people. Infection Control and Hospital E, Epidemiology, 27(2), 204-207.

Purcell, K., \& Fergie, J. (2005). Epidemic of community-acquired methicillin-resistant Staphylococcus aureus infections: A 14-year study at Driscoll children's hospital. Archive of Pediatrics and Adolescent Medicine, 159(10), 980-985.

Rejendran, P., Young, D., Maurer, T., Chambers, H., Perdreau-Remington, F., Ro, P., et al. (2007). Randomized, double-blind, placebo-controlled trial of cephalexin for treatment of uncomplicated skin abscesses in a population at risk for community-acquired methicillin-resistant Staphylococcus aureus infection. Antimicrobial Agents and Chemotherapy, 51(11), 4044-4048.

Rihn, J., Posfay-Barbe, K., Harner, C., Macurak, A., Farley, A., Greenawalt, K., et al. (2005). Community-acquired methicillin-resistant Staphylococcus aureus outbreak in a local high school football team unsuccessful intervention. Pediatric Infectious Disease Journal, 24(9), 841-843.

Robinson, D., Kearns, A., Holmes, A., Morrison, D., Grundmann, H., Edwards, G., et al. (2005). Re-emergence of early pandemic Staphylococcus aureus as a community-acquired methicillin-resistant clone. Lancet, 365, 1256-1258.

Rybak, M., Lomaestro, B., Roschafer, J., Moellering, R., Craig, W., Billeter, M., et al.,(2009). Therapeutic monitoring of vancomycin in adult patients: A consensus review of the American Society of Health-System Pharmacists, the Infectious Disease Society of America, and the Society of Infectious Diseases Pharmacists. American Journal of Health-System Pharmacists, 66, 82-98.

Salgado, C., Farr, B., \& Calfee, D. (2003). Community-acquired methicillin-resistant Staphylococcus aureus: A meta-analysis of prevalence and risk factors. Clinical Infectious Diseases, 36, 131-139.

Sattler, C., Mason, Jr., E., \& Kaplan, S. (2002). Prospective comparison of risk factors and demographic and clinical characteristics of community-acquired, methicillin-resistant versus methicillin-susceptible Staphylococcus aureus infection in children. Pediatric Infectious Disease Journal, 21(10), 910-916.

Simor, A., Philips, E., McGee, A., Konalinka, A., Loeb, M., Devlin, R., et al. (2007). Randomized controlled trial of chlorhexidine gluconate for washing, intranasal mupirocin, and rifampin and doxycycline versus no treatment for the eradication of methicillin-resistant Staphylococcus aureus colonization. Clinical Infectious Disease, 44, 178-184.

Stevens, D., Bisno, A., Chambers, H., Everett, E., Dellinger, P., Goldstein, E., et al. (2005). Practice guidelines for the diagnosis and management of skin and soft-tissue infections. Clinical Infectious Diseases, 41, 1371-1830.

Stevenson, K., Searle, K., Stoddard, G. \& Samore, M. (2005). Methicillin-resistant Staphylococcus aureus and vancomycin-resistant enterococci in rural communities, western United States. Emerging Infectious Diseases, 11(6), 895-903.

Vandenesch, F., Naimi, T., Enright, M., Lina, G., Nimmo, F., Heffernan, H., et al. (2003). Community-acquired methicillin resistant Staphylococcus aureus carrying panton-valentine leukocidin genes: Worldwide emergence. Emerging Infectious Diseases, 9(8), 978-984.

Wannet, W., Heck, M., Pluister, G., Spalburg, E., Santen, M., Huijsdens, X., et al. (2004). Panton-valentine leukocidin positive MRSA in 2003: The Dutch situation. Europosurveillance, 12 (2), 1202-1222.

Wang, R., Braughton, K., Kretschmer, D., Bach, T., Queck, S., Li, M., et al. (2007). Identification of novel cytolytic peptides as key virulence determinants for community-associated MRSA. Nature Medicine, Letters. Advance online publication. Retrieved February 22, 2008, from http://www.nature.com/naturemedicine

Weese, S., Dick, H., Willey, B., McGeer, A., Kreiswirth, B., Innis, B., et al. (2006). Suspected transmission of methicillin-resistant Staphylococcus aureus between domestic pets and humans in veterinary clinics and in the household. Veterinarian Microbiology, 115(1-5), 148-155. 
Winland-Brown, J., Porter, B., \& Leik, M. (2007). Skin problems. In L. M. Dunphy, J. W. Brown, B. O. Porter, \& D. J. Thomas (Eds.), Primary care: The art and science of advanced practice nursing (pp. 131-228). Phildelphia: F.A. Davis Company.

Zafar, U., Johnson, L, Hanna, M., Riederer, K., Sharma, M., Fakih, M., et al. (2007). Prevalence of nasal colonization among patients with community-associated methicillin-resistant Staphylococcus aureus infection and their household contacts. Infection Control and Hospital Epidemiology, 28(6), 966-969.

Zaoutis, T., Toltzis, P., Chu, J., Abrams, T., Dul, M., Kim, J., et al. (2006). Clinical and molecular epidemiology of community-acquired

methicillin-resistant Staphylococcus aureus infections among children with risk factors for health care-associated infection: 2001-2003. Pediatric Infectious Disease Journal, 25(4), 343-348.

\section{Supporting Information}

Additional supporting information may be found in the online version of this article:

Table S1. Epidemiology table.

Please note: Wiley-Blackwell is not responsible for the content or functionality of any supporting materials supplied by the authors. Any queries (other than missing material) should be directed to the corresponding author for the article. 